\title{
Association Between Alcohol Consumption and Nocturnal Leg Cramps in Patients Over 60 Years Old: A Case-Control Study
}

Cbloé Delacour, $M D^{1}$

Juliette Chambe, $M D^{1}$

François Lefebvre, $M D^{2}$

Claire Bodot, $M D^{1}$

Elodie Bigerel, $M D^{1}$

Laetitia Epifani, $M D^{1}$

Céline Granda, $M D^{1}$

Dagmar M. Haller, MD, $P b D^{3}$

Hubert Maisonneuve, $M D^{1,3}$

${ }^{1}$ General Medicine Department, Faculty of Medicine, University of Strasbourg, Strasbourg, France

${ }^{2}$ Public Health Department, Faculty of Medicine, University of Strasbourg, Strasbourg, France

${ }^{3}$ Primary Care Unit, Faculty of Medicine, University of Geneva, Geneva, Switzerland

AC Annals Journal Club selection; see inside back cover or http://www.ann fammed.org/AJC/.

Conflicts of interest: authors report none.

\section{CORRESPONDING AUTHOR}

Chloé Delacour, MD

General Medicine Department,

Faculty of Medicine

University of Strasbourg, Strasbourg, France

4 rue Kirschleger

67000 Strasbourg France

chloe.delacour@unistra.fr

\begin{abstract}
PURPOSE Nocturnal leg cramps are a specific kind of cramps affecting almost one-half of patients aged 60 years and older. They reduce patients' quality of sleep and have a negative impact on their quality of life. The aim of this study was to evaluate the association between nocturnal leg cramps and the consumption of alcoholic beverages in patients aged 60 years and older attending general practices.
\end{abstract}

METHODS Case-control study with a Bayesian approach for sensitivity analysis. Participants were voluntary ambulatory patients aged 60 years and older consulting their family doctor. They were recruited in 67 general practices across the Alsace region. Cases (patients having cramps), were matched with controls (patients free from cramps) for age, sex, medical history, and medications known to trigger cramps. Alcohol consumption was assessed through a standardized food frequency questionnaire.

RESULTS We found an association between the global consumption of alcoholic beverages and nocturnal leg cramps (OR $=6.5,95 \%$ credibility interval, 1.68 38.05; posterior probability $99.82 \%$ ).

CONCLUSION We identified an association between alcohol consumption and nocturnal leg cramps among patients aged 60 years and older attending general practices. These findings have implications for the prevention of cramps.

Ann Fam Med 2018;16:296-301. https://doi.org/10.1370/afm.2238.

\section{INTRODUCTION}

The common definition of cramps is episodes of pain due to sudden, intense, and involuntary contractions of muscles lasting up to several minutes. ${ }^{1,2}$ Resolution is either spontaneous or helped by stretching the contracted muscle. ${ }^{3}$ Lower limbs are the first to be affected, especially the calf. ${ }^{4,5}$ A specific kind of cramps occurring at night or during rest time has been identified as nocturnal leg cramps (NLC). ${ }^{5.7}$

The prevalence of NLC was studied in 2012 in a French population of patients aged 60 years and older. ${ }^{8}$ Among this population, 46\% reported NLC, $15 \%$ experienced cramps more than 3 times a month, and $31 \%$ were awakened by them.

Nocturnal leg cramps reduce quality of sleep and have a negative impact on physical aspects of health-related quality of life. ${ }^{9}$ Nevertheless, patients rarely report their NLC symptoms to physicians and effective and safe treatments are lacking. ${ }^{10-13}$

Even though some specific medical conditions and drug treatments have been identified as causes of muscle cramps, ${ }^{5,14}$ most cramps are considered idiopathic ${ }^{6}$ and their exact pathophysiology remains unknown. ${ }^{15-17}$ Thus far, there is a lack of observational studies, especially in primary care, focusing on lifestyle factors associated with NLC. ${ }^{18,19}$ According to popular belief, the consumption of alcoholic beverages may cause mus- 
cular stiffness. As far as we know, however, no studies have yet explored the association between alcohol consumption and NLC in elderly people. ${ }^{20}$

Our aim was to assess the association between NLC and the consumption of alcoholic beverages in elderly patients.

\section{METHODS}

\section{Study Design}

The study was conducted within the Strasbourg General Medicine Department practice-based research network. It was part of a larger study exploring the association between lifestyle and NLC. ${ }^{21}$

We carried out a case-control study in 2013. The study consisted of a 6-month screening phase which was followed by an 11-month data collection phase.

The STrengthening the Reporting of OBservational studies in Epidemiology (STROBE) statement was used to guide the reporting of the study. The study was approved by the Ethics Committee of the Mulhouse Hospital.

\section{Study Population}

The trial was carried out in 67 general practices across the Alsace region, all members of the General Medicine Department practice-based research network.

Patients included were aged 60 years or older, autonomous in their daily life, and had consulted their general practitioner for any reason. The minimum age limit was set at 60 because younger patients are less likely to suffer from cramps. ${ }^{3,4}$

The pools of cases and controls were generated during the consultation time. General practitioners recruited patients prospectively using a systematic step of 1 in 4 attending patients aged 60 years or older. Anonymized clinical data was collected with a screening questionnaire and entered into an electronic database for future contact. The existence of leg cramps was determined at the time of the consultation.

\section{Case Control Matching}

Cases were defined as patients aged 60 years and older currently having NLC. Controls were defined as patients free from any kind of rest cramps. Each case was matched with 1 control. Matching criteria were: same sex, same age group (age difference less than 5 years), with at least 1 of the following elements in common: 1 medication (Supplemental Appendix 1, available at http://www.annfammed.org/ content/16/4/296/suppl/DC1/) or 1 medical condition (Supplemental Appendix 2, available at http://www. annfammed.org/content/16/4/296/suppl/DC1/) suspected of triggering cramps. $5,6,14,18$

\section{Data Collection}

We collected data at 2 different times. Initially, during the consultation time, clinical data from all eligible patients were recorded in a database under encoded numbers. Data included sex, age, medical history, medications, and characteristics of muscular cramps. Later, after case/control matching, investigators phoned the patients to schedule an interview to explain and administer the food frequency questionnaire. When patients were registered as lost to follow-up, a new matching was done when possible.

\section{Measuring Instruments/Outcome Measures}

The screening questionnaire was based on a literature review $^{4,5,7,8,22-24}$ and focused on demographics, cramp presence and main features, medical history, and treatments. The questionnaire was then evaluated by 8 general practitioners and amended. The final questionnaire was explicit in defining cramps as a painful involuntary muscle contraction when resting, lasting from a few seconds to a few minutes. . $^{-5,7,8,14,22}$

The food frequency questionnaire appears to be the best method to evaluate individual dietary intake among general practice patients. ${ }^{25}$ In this study, we used the food frequency questionnaire from the French Cohort Study (E3N) of the European Prospective Investigation into Diet and Cancer (EPIC) Study. The E3N food frequency questionnaire was validated to classify study subjects according to their food or nutrient intake over a 1 -year period. ${ }^{26,27}$

The beverages explored by E3N food frequency questionnaire are presented in Supplemental Appendix 3, available at http://www.annfammed.org/ content/16/4/296/suppl/DC1/. For each participant, we computed the total 1-week volume of alcoholic beverage from the 1-week consumption of each alcoholic beverage presented in Supplemental Appendix 3. Using a food and drink composition table, we converted the volumes to a 1-week mass of alcohol consumed. ${ }^{28}$

Patients were distributed into groups of consumers and nonconsumers of alcoholic beverage. When patients used an alcoholic beverage less than once a week, they were distributed in the nonconsumers group.

\section{Statistical Analysis}

We assumed that $67 \%$ of the controls were consuming alcohol once a week. ${ }^{29}$ Therefore we calculated the sample size based on an assumed odds ratio of 3, with $80 \%$ power at a $5 \%$ level of significance. Given the fact that we carried out a case-control study with 1 case for each control, ignoring the clustering effect, we estimated that 76 subjects would be required in each group.

We compared consumers and nonconsumers of alcoholic beverages with Bayesian conditional logis- 
tic and hierarchical linear regressions to take into account the matching. In the absence of an informative prior distribution based on the clinic, we used a normal distribution of the odds ratios of the association between the consumption of alcohol and the presence of cramps. We used a mean equal to 0 and a variance equal to 10 for conditional logistic regression and equal to 100 for linear regression. In order to confirm the robustness of the models, we performed sensibility analyses with all the data, by modifying the prior means and prior odds ratios and by creating hierarchical logistic models. For each model, 100,000 iterations were used after a burning of 10,000 iterations. The thinning used was 1 . Convergence and auto-correlation were checked after each model

Then, we explored the linear relationship between mass of alcohol consumption and odds of cramps with a Bayesian univariate and multivariate conditional logistic regression. We also computed credibility intervals and posterior probabilities. In a Bayesian approach a posterior probability (PP) below 95\% means that no difference has been identified with sufficient probability.

Bayesian inference was chosen because this statistical method enables the inclusion of prior information. The parameter estimates are issued with credibility intervals, providing a more intuitive interpretation than the one that is almost always wrongly given when the (frequentist) confidence interval is used. The Bayesian approach is better adapted to studies where the amount of data are limited. The conclusions are formulated in terms of probability, taking into account the given data. ${ }^{30-33}$

All the analyses were performed with R 3.3.3 and WinBUGS software, version 1.4.3 (The BUGS Project, MRC Biostatistics Unit, University of Cambridge). ${ }^{34}$

\section{RESULTS}

\section{Study Population Characteristics}

Between January and June 2013, 849 patients were approached. From that group, 492 voluntary patients were listed in the database for further contact and of those, 222 subjects agreed to meet. From the collected questionnaires, we matched 70 pairs (Figure 1). Of the 70 pairs, 40 were men (57\%). Patients were aged 60 to 86 years. The mean age (SD) was 67.8 (6.3) for cases and 67.9 (6.3) for controls. Cases and controls were similar according to age group, medications, and medical conditions (Table 1).

\section{Consumption and Cramps}

Among the 140 participants: 24 never consumed alcoholic beverages and 116 consumed alcoholic beverage on a regular basis. Weekly, cases consumed a median of
$94 \mathrm{~g}$ of alcohol (interquartile range 211), while controls consumed $66 \mathrm{~g}$ (interquartile range 198) (Figure 2).

The concordance or discordance between cases and controls for the consumption of alcohol is shown in Supplemental Table 1, http://www.annfammed.org/ content/16/4/296/suppl/DC1/). Among the 70 pairs, 14 differed according to the consumption of alcoholic beverages.

We found an association between the global consumption of alcoholic beverages and NLC. Patients drinking alcohol at least once a week had an odds ratio of 6.5 of having cramps (95\% credibility interval, 1.68-38.05; posterior probability $99.82 \%)$. There was no linear relationship between amount of alcohol used and odds of cramps. The odds ratios for an additional intake of 1 gram of alcohol were 1.001 for the univariate model and 1.000 for the multivariate model. Both had $95 \%$ creditability intervals of $0.98-1.01$. The posterior probabilities were nonsignificant (under 95\%).

\section{DISCUSSION}

\section{Main Results}

We found a strong association between the global consumption of alcoholic beverages and NLC. To the best of our knowledge, this is the first study to measure such a link.

\section{Possible Explanations for the Association Between Alcohol Use and NLC}

Alcohol consumption is responsible for many medical conditions, from gout ${ }^{35,36}$ to heart attacks, ${ }^{37}$ neuropathy, and myopathy. ${ }^{38-40}$ We found only 2 reported cases of cramps, without any signs of myopathy, that were presumably due to the consumption of alcoholic

Figure 1. Study population screening, selection, and matching.

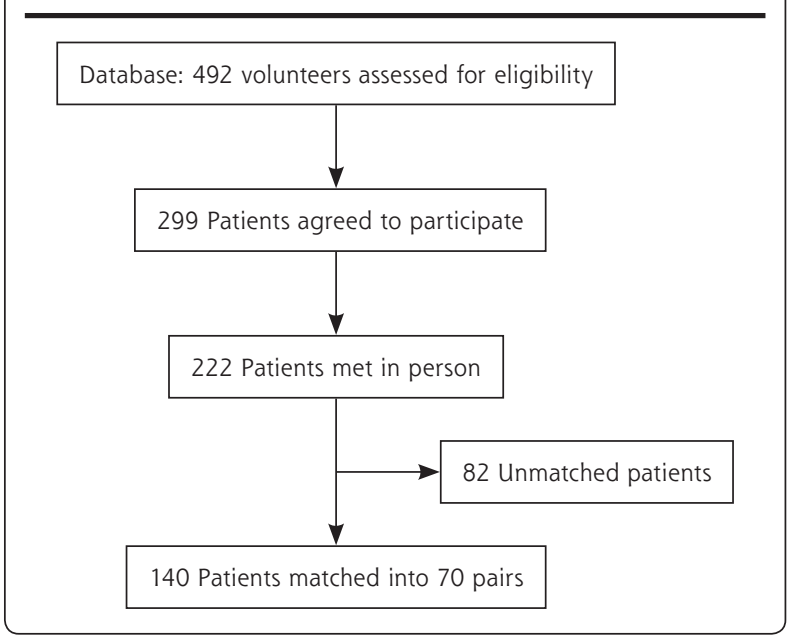


Table 1. Comparison of Age Groups, Medications, and Medical Conditions of Cases and Controls

\begin{tabular}{|c|c|c|c|c|c|c|c|}
\hline & Case & Control & $P$ value $^{a}$ & & Case & Control & $P$ value $^{a}$ \\
\hline \multicolumn{8}{|l|}{ Age Group } \\
\hline $60-64$ & 26 & 27 & .86 & Medication (continued) & & & \\
\hline $65-69$ & 20 & 18 & .70 & Others & & & \\
\hline $70-74$ & 9 & 13 & .35 & Bisphosphonates & 0 & 1 & 1 \\
\hline $75-79$ & 13 & 9 & .35 & Anti-epileptic drug & 0 & 1 & 1 \\
\hline$\geq 80$ & 2 & 3 & .65 & NSAIDs & 1 & 0 & 1 \\
\hline Medication & & & & Proton pump inhibitor & 11 & 11 & 1 \\
\hline No medication & 15 & 13 & .70 & Alpha-blocker & 3 & 0 & .25 \\
\hline \multicolumn{4}{|l|}{ Anti hypertensive drugs } & Melatonin & 0 & 0 & \\
\hline Thiazides & 2 & 4 & .69 & Progestogen & 1 & 0 & 1 \\
\hline Calcium channel blockers & 10 & 8 & .63 & Selective estrogen receptor & 0 & 0 & \\
\hline Beta-blockers & 20 & 13 & .21 & modulator & & & \\
\hline Loop diuretics & 2 & 3 & 1 & GnRH analogue & 0 & 0 & \\
\hline ACE/ARBS & 18 & 11 & .19 & Others & 88 & 92 & .75 \\
\hline Potassium-sparing diuretics & 2 & 4 & .69 & Medical Conditions & & & \\
\hline Centrally-acting agents & 3 & 2 & 1 & Hypertension & 51 & 49 & .71 \\
\hline \multirow{2}{*}{$\begin{array}{l}\text { Association ACE/ARBs } \\
\text { + thiazides }\end{array}$} & \multirow[t]{2}{*}{11} & \multirow[t]{2}{*}{12} & \multirow[t]{2}{*}{.82} & Severe arteriopathy & 2 & 1 & 1 \\
\hline & & & & Severe venous insufficiency & 4 & 2 & .68 \\
\hline Association ACE/ARBs + CCBs & 5 & 2 & .45 & Diabetes & 14 & 12 & .66 \\
\hline \multirow{2}{*}{$\begin{array}{l}\text { Association beta-blockers } \\
+ \text { thiazides }\end{array}$} & \multirow[t]{2}{*}{0} & \multirow[t]{2}{*}{3} & \multirow[t]{2}{*}{.25} & Hypothyroidy & 9 & 7 & .60 \\
\hline & & & & Hypoparathyroidy & 0 & 1 & 1 \\
\hline \multicolumn{4}{|l|}{ Lipid lowering drugs } & Severe renal insufficiency & 6 & 1 & .11 \\
\hline Statin & 22 & 23 & \multirow[t]{2}{*}{88} & Peripheral neuropathy & 3 & 0 & .24 \\
\hline Ezetrol & 0 & 0 & & Restless leg syndrome & 1 & 0 & 1 \\
\hline \multicolumn{4}{|l|}{ Inhalated medication } & Alcohol addiction & 0 & 2 & .50 \\
\hline Beta-mimetics & 3 & 4 & 1 & Cancer (not in remission) & 2 & 2 & 1 \\
\hline Anti-leukotriene & 1 & 1 & 1 & Others & 55 & 59 & .38 \\
\hline
\end{tabular}

beverages. ${ }^{20,41}$ Cramps are one of the symptoms of alcoholic myopathy and is characterized histologically by selective atrophy of type II fibers. ${ }^{40,42}$ We hypothesize that, since the same defect is observed in aging individuals and in people with sedentary lifestyles, ${ }^{43,44}$ chronic alcohol intake may increase the destruction

Figure 2. Comparison of the mass of alcohol consumed per week by cases and controls.

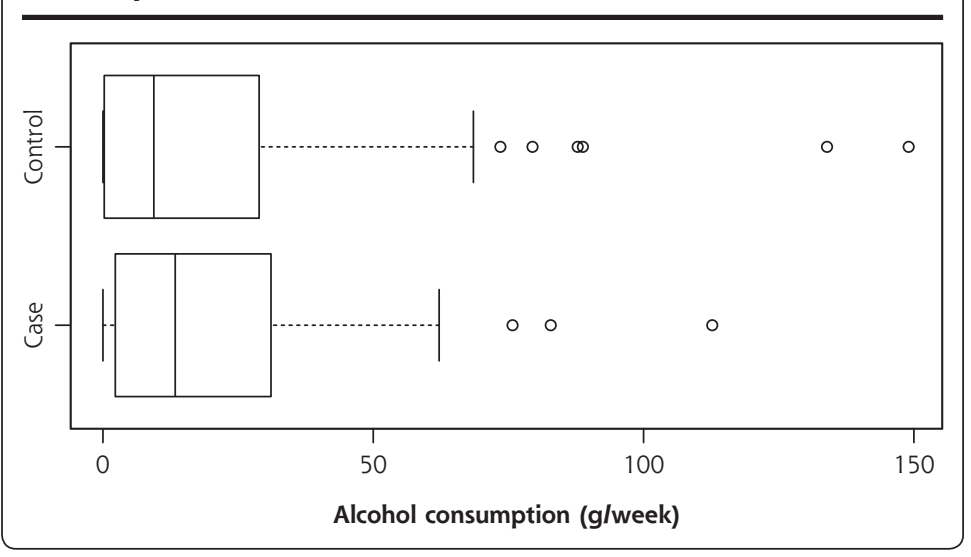

of type II fibers in the elderly and make them more vulnerable to NLC. ${ }^{40}$ This remains to be confirmed. To our knowledge, the literature does not provide any evidence linking alcoholic neuropathy and cramps. Binge drinkers seem to be more at risk for complications such as heart attacks than people who chronically consume alcohol..$^{37}$ Our study did not specifically explore the modality of alcohol intake, but binge drinking is rare among the elderly French population. An international multicenter cohort study would be necessary to confirm a causal link between alcohol consumption and NLC, and to determine a threshold for acute and chronic consumption.

\section{Future Research and Implications for Practice}

Further research should be undertaken to investigate the existence of an alcohol dose-related effect. Our study offers practitioners 2 major new elements for their daily practice. Advising patients about 
the impact of alcohol consumption on NLC may be an effective way to prevent these painful episodes. Alternatively, discussing NLC may be another icebreaker for general practitioners to approach alcohol misuse.

\section{Strengths and Limitations}

Visual impairment, as well as the time needed to complete the questionnaire may have discouraged some participants, although the use of this auto-questionnaire had previously been validated. ${ }^{27,45}$ The E3N food frequency questionnaire is a recall questionnaire administered at 1 time point, but its accuracy, the period of 1 month allocated to complete the questionnaire, and the aid of a research assistant before and after the data collection limit memory and lack of precision bias. Nevertheless, all the information remains declarative.

Our population includes a greater proportion of men than a standardized French population (Supplemental Table 2, http://www.annfammed.org/ content/16/4/296/supp1/DC1). According to the literature, $79 \%$ of French men consume alcohol weekly while only $47 \%$ of women do the same. ${ }^{29,46}$ The impact of the difference in gender remains unknown, but the matching based on gender aimed to minimize it.

In summary, to our knowledge, this study is the first to focus on the association between the global consumption of alcoholic beverages and NLC in a primary care environment. We found a strong association between the consumption of alcoholic beverages and NLC. More studies are needed to evaluate the existence of a causal link and to determine the pathophysiology of cramps and the impact of alcohol on it.

To read or post commentaries in response to this article, see it online at http://www.AnnFamMed.org/content/16/4/296.

Key words: primary health care; muscle cramp; alcohol drinking

Submitted February 23, 2017; submitted, revised, December 21, 2017; accepted March 6, 2018.

Funding support: This project was supported by institutional funding from the Faculty of Medicine, University of Strasbourg.

Previous presentations: Presented as a short communication at the $9^{\text {th }}$ Annual Conference of the French College of General Medicine; March 2015; Paris, France; and as a short communication at the 21st Wonca Europe Conference; June 15-18, 2016; Copenhagen, Denmark.

Acknowledgments: The authors thank the members of the Strasbourg general medicine department practiced-based research network (Martin Class, Lucie Walter, Delphine Nicolle, and Orianne Michel Grosjean) for their collaboration in the data collection, Jennifer Hasselgard-Rowe, University of Geneva; Georgina Praus-Fox and Jean-Pascal Fournier, MD, University of Nantes, for assisting in the manuscript preparation and the medical service of the regional health insurance.

Supplementary materials: Available at http://www.AnnFamMed. org/content/16/4/296/suppl/DC1/.

\section{References}

1. Parisi L, Pierelli F, Amabile G, et al. Muscular cramps: proposals for a new classification. Acta Neurol Scand. 2003;107(3):176-186.

2. Stern LZ, Bernick C. Muscle cramps. In: Walker HK, Hall WD, Hurst JW, eds. Clinical Methods: The History, Physical, and Laboratory Examinations. 3rd ed. Boston, MA: Butterworths; 1990.

3. Miller TM, Layzer RB. Muscle cramps. Muscle Nerve. 2005;32(4): 431-442.

4. Naylor JR, Young JB. A general population survey of rest cramps. Age Ageing. 1994;23(5):418-420.

5. Rabbitt L, Mulkerrin EC, O'Keeffe ST. A review of nocturnal leg cramps in older people. Age Ageing. 2016;45(6):776-782.

6. Monderer RS, Wu WP, Thorpy MJ. Nocturnal leg cramps. Curr Neurol Neurosci Rep. 2010;10(1):53-59.

7. Oboler SK, Prochazka AV, Meyer TJ. Leg symptoms in outpatient veterans. West J Med. 1991;155(3):256-259.

8. Maisonneuve $\mathrm{H}$, Chambe J, Delacour $\mathrm{C}$, et al. Prevalence of cramps in patients over the age of 60 in primary care: a cross sectional study. BMC Fam Pract. 2016;17(1):111.

9. Hawke F, Chuter V, Burns J. Impact of nocturnal calf cramping on quality of sleep and health-related quality of life. Qual Life Res. 2013;22(6):1281-1286.

10. El-Tawil S, Al Musa T, Valli $H$, et al. Quinine for muscle cramps. Cochrane Database Syst Rev. 2015;4(4):CD005044.

11. Katzberg HD, Khan AH, So YT. Assessment: symptomatic treatment for muscle cramps (an evidence-based review): report of the therapeutics and technology assessment subcommittee of the American academy of neurology. Neurology. 2010;74(8):691-696.

12. Garrison SR, Allan GM, Sekhon RK, Musini VM, Khan KM. Magnesium for skeletal muscle cramps. Cochrane Database Syst Rev. 2012; 9(9):CD009402.

13. Blyton F, Chuter V, Walter KEL, Burns J. Non-drug therapies for lower limb muscle cramps. Cochrane Database Syst Rev. 2012;1: CD008496.

14. Garrison SR, Dormuth CR, Morrow RL, Carney GA, Khan KM. Nocturnal leg cramps and prescription use that precedes them: a sequence symmetry analysis. Arch Intern Med. 2012;172(2):120-126.

15. Lopate G, Streif E, Harms M, Weihl C, Pestronk A. Cramps and small-fiber neuropathy. Muscle Nerve. 2013;48(2):252-255.

16. Katzberg HD. Neurogenic muscle cramps. J Neurol. 2015;262(8): 1814-1821.

17. Jansen PHP, Joosten EMG, Vingerhoets HM. Muscle cramp: main theories as to aetiology. Eur Arch Psychiatry Neurol Sci. 1990;239(5): 337-342.

18. Hawke F, Chuter V, Burns J. Factors associated with night-time calf muscle cramps: a case-control study. Muscle Nerve. 2013;47(3): 339-343.

19. Garrison SR, Dormuth CR, Morrow RL, Carney GA, Khan KM. Seasonal effects on the occurrence of nocturnal leg cramps: a prospective cohort study. CMAJ. 2015;187(4):248-253.

20. Blank NK. Alcohol ingestion and muscle spasms. JAMA. 1979; 241(15):1574.

21. Lorenzo M, Schaeffer M, Haller DM, Maisonneuve H. Treatment of nocturnal leg cramps by primary care patients over the age of 60 . Fam Pract. 2018;35(1):29-33..

22. Serratrice G. Les crampes musculaires essentielles [Primary muscle cramps]. Rev Neurol (Paris). 2008;164(5):416-425.

23. Bouhassira D, Attal N, Alchaar $\mathrm{H}$, et al. Comparison of pain syndromes associated with nervous or somatic lesions and development of a new neuropathic pain diagnostic questionnaire (DN4). Pain. 2005;114(1-2):29-36. 
24. American Academy of Sleep Medicine. International Classification of Sleep Disorders - Second Edition (ICSD-2). Darien, IL: American Academy of Sleep Medicine; 2005.

25. Barrat E, Aubineau N, Maillot M, Derbord É, Barthes P, Lescuyer $J-F$, et al. Repeatability and relative validity of a quantitative foodfrequency questionnaire among French adults. Food Nutr Res. 2012; 56. http://foodandnutritionresearch.net/index.php/fnr/article/ view/472. Published Oct 30, 2012. Accessed Oct 6, 2016.

26. Lucas F, Niravong M, Villeminot S, Kaaks R, Clavel-Chapelon F. Estimation of food portion size using photographs: validity, strengths, weaknesses and recommendations. J Hum Nutr Diet. 1995;8(1):65-74.

27. Liere V, J M, Lucas F, Clavel F, Slimani N, Villeminot S. Relative validity and reproducibility of a French dietary history questionnaire. Int J Epidemiol. 1997;26(suppl_1):S128-136.

28. Favier J-C, Ireland-Ripert J, Toque C, Feinberg M. Répertoire général des aliments: table de composition =composition tables. Paris, France:Technique \& Documentation;INRA; 1995. http://www. documentation.ird.fr/hor/fdi:010009113. Published 1995. Accessed Oct 6, 2016.

29. Beck F, Richard JB. La consommation d'alcool en France. La Presse médicale. 2014;43(10):1067-1079.

30. Hox JJCM, van de Schoot R, Matthijsse $S$. How few countries will do? Comparative survey analysis from a Bayesian perspective. Surv Res Methods. 2012;6(2):87-93.

31. Lee S-Y, Song X-Y. Evaluation of the Bayesian and Maximum Likelihood Approaches in Analyzing Structural Equation Models with Small Sample Sizes. Multivariate Behav Res. 2004;39(4):653-686.

32. Van de Schoot R, Broere JJ, Perryck KH, Zondervan-Zwijnenburg $M$, Loey NE van. Analyzing small data sets using Bayesian estimation: the case of posttraumatic stress symptoms following mechanical ventilation in burn survivors. Eur J Psychotraumatology. 2015;6: 10.3402/ejpt.v6.25216.

33. van de Schoot R, Kaplan D, Denissen J, Asendorpf JB, Neyer FJ, van Aken MAG. A gentle introduction to bayesian analysis: applications to developmental research. Child Dev. 2014;85(3):842-860.
34. The BUGS Project, MRC Biostatistics Unit, University of Cambridge. Website. https://www.mrc-bsu.cam.ac.uk/software/bugs/. Accessed Feb 20, 2017.

35. MacFarlane LA, Kim SC. Gout: a review of nonmodifiable and modifiable risk factors. Rheum Dis Clin North Am. 2014;40(4):581-604.

36. Neogi T, Chen C, Niu J, Chaisson C, Hunter DJ, Zhang Y. Alcohol quantity and type on risk of recurrent gout attacks: an internetbased case-crossover study. Am J Med. 2014;127(4):311-318.

37. Ruidavets J-B, Ducimetière $P$, Evans $A$, et al. Patterns of alcohol consumption and ischaemic heart disease in culturally divergent countries: the Prospective Epidemiological Study of Myocardial Infarction (PRIME). BMJ. 2010;341:c6077.

38. Preedy VR, Salisbury JR, Peters TJ. Alcoholic muscle disease: features and mechanisms. J Pathol. 1994;173(4):309-315.

39. Spector R, Choudhury A, Cancilla P, Lakin R. Alcohol myopathy. Diagnosis by alcohol challenge. JAMA. 1979;242(15):1648-1649.

40. Martin F, Ward K, Slavin G, Levi J, Peters TJ. Alcoholic skeletal myopathy, a clinical and pathological study. Q J Med. 1985;55(218):233-251.

41. Coffman J. Questions and answers: alcohol ingestion and leg cramps. JAMA. 1978;240(20):2196-2196.

42. Slavin G, Martin F, Ward P, Levi J, Peters T. Chronic alcohol excess is associated with selective but reversible injury to type $2 \mathrm{~B}$ muscle fibres. J Clin Pathol. 1983;36(7):772-777.

43. Grimby G. Physical activity and effects of muscle training in the elderly. Ann Clin Res. 1988;20(1-2):62-66.

44. Lexell J, Taylor CC, Sjöström M. What is the cause of the ageing atrophy? Total number, size and proportion of different fiber types studied in whole vastus lateralis muscle from 15- to 83 -year-old men. J Neurol Sci. 1988;84(2-3):275-294.

45. Touvier $M$, Niravong $M$, Volatier J-L, et al. Dietary patterns associated with vitamin/mineral supplement use and smoking among women of the E3N-EPIC cohort. Eur J Clin Nutr. 2009;63(1):39-47.

46. Hill C, Laplanche A. La consommation d'alcool est trop élevée en France. Presse Médicale. 2010;39(7-8):e158-164. 